\title{
Women in academic psychiatry
}

\author{
Rina Dutta, ${ }^{1 \dagger}$ Sarah L. Hawkes, ${ }^{1 \dagger}$ Amy C. Iversen, ${ }^{1}$ Louise Howard ${ }^{2}$
}

The Psychiatrist (2010), 34, 313-317, doi: 10.1192/pb.bp.109.028134

${ }^{1}$ Department of Psychological Medicine and Psychiatry, Institute of Psychiatry, King's College London; ${ }^{2}$ Health Service and Population Research Department, Institute of Psychiatry, King's College London

Correspondence to Rina Dutta (rina.2.dutta@kcl.ac.uk)
Summary Across academic medicine, including psychiatry, women are underrepresented in senior positions. Various reasons have been put forward, for example the lack of high-ranking female role models or mentors and a reduced rate of career progression for women compared with men. Mentoring has been shown to be a popular and feasible intervention which can improve the success of those perceived as disadvantaged groups (in this case women) by having an important impact on personal development, career guidance and research productivity.

Declaration of interest None.
In the past 40 years, the proportion of women selected for medical school in the UK has risen from just $20 \%$ to approximately $60-65 \%{ }^{1}$, reflecting the determination, ambition and ability of young women. This has been accompanied by increasing numbers of women selecting a career in psychiatry. However, in the higher echelons of academic psychiatry, as with other branches of academic medicine, women are under-represented. Within academic psychiatry, just $13 \%$ of clinical professors are women compared with $29 \%$ of clinical lecturers. ${ }^{2}$ Women make up $35 \%$ of the Academic Psychiatry Faculty of the Royal College of Psychiatrists, comprising $40 \%$ of research fellows but only $10 \%$ of professors. At the Academy of Medical Sciences, 55 fellows have an interest in psychiatry, of whom 9 are female (16\%), whereas the British Academy has 34 fellows in psychology, 10 of whom are female (29\%).

In wider academic medicine in the UK the situation is no better. Despite an increase in the proportion of women in medical schools, both as students and staff, women remain under-represented compared with their male counterparts at senior levels. The Medical Schools Council report that the number of women in clinical academia decreases at each grade of the academic career ladder; only $11 \%$ of clinical professorial staff in medicine are women, compared with $36 \%$ of clinical lecturers. ${ }^{2}$ Furthermore, the Council recently reported that six medical schools across all specialties reported no female clinical professors in post in the last round of data collection. On the other hand, according to the Professional Standards Department at the Royal College of Psychiatrists, of the 22 postgraduate deanery schools, 7 have female heads of psychiatry (32\%) and the Lead Dean is a woman (Professor Jacky Hayden).

In the USA, similar statistics emerge for percentages of senior academic female psychiatrists: in 2002, women made

These authors contributed equally to this work. up $37 \%$ of faculty in departments of psychiatry, with $29 \%$ of associate professors and $15 \%$ of full professors being women. Only eight women had chaired a medical school psychiatry department and no female psychiatrist had been dean of a medical school in the USA. ${ }^{3}$

In addition to the actual proportions of women in academic medicine, there is clear evidence that women face barriers to career progression. Women are less likely to achieve academic promotion than male faculty members with a similar length of appointment; ${ }^{4}$ five times more likely to leave the academic workforce at an earlier point in their career than men; ${ }^{5}$ less likely to be granted research funding, ${ }^{6}$ mainly because of their under-representation in senior grades, ${ }^{7}$ and have a lower salary than men which is not fully accounted for by difference in academic rank. ${ }^{8}$ Men are more likely to be involved in a range of high-profile academic activities, or to have a higher publication record than women. ${ }^{9}$ They are more likely than women to be represented on the editorial boards of journals and be appointed to the position of editor-in-chief, ${ }^{10}$ or to sit on university committees. ${ }^{5}$

At an early point in one's career, when it is customary to work full time, women often choose to start a family and take time out. This means that although their length of appointment may be equivalent to that of men, actual working time may be considerably shorter. Female academics with children report slower career progression and greater obstacles to academic success compared with those without children or their male counterparts. ${ }^{\text {II }}$ Research carried out for the British Medical Association report Women in Academic Medicine ${ }^{12}$ found that females working in medical higher education were more likely than males to identify personal factors that had been detrimental to their academic careers. These included lack of ability to easily move location, having followed an unconventional career path, having followed their partner's career, having periods of less than full-time working and having taken a career break. 


\section{Barriers to success}

\section{Is it a question of time?}

The absence of women in senior roles has been explained as a consequence of women's historical under-representation at undergraduate level, and that over time, with more women entering medical school, this would likely correct itself. However, as yet there is no good evidence for this. Despite the steady increase in the number of female medical school graduates in both the USA and the UK in the past four decades, there has been no substantial increase in the numbers of women in senior roles. ${ }^{13}$ One study in fact suggests that women in more recent cohorts are less likely to be promoted to senior positions than women from older cohorts. ${ }^{4}$ It is possible, however, that this could be a consequence of insufficient follow-up time of more recent cohorts. Alternative career patterns, where women resume full-time academic research after completing their family, mean that many may not attain a professorial role until they are considerably older than men.

\section{Are women inferior academically?}

One possible hypothesis is that there are fewer women in senior positions in academic psychiatry because they do not perform as well as men either at medical school or at a postgraduate level. However, there is considerable evidence to the contrary; more women than men undertake intercalated degrees and women often gain a higher intercalated degree classification than their male counterparts in degrees with a substantial research component. ${ }^{2}$ Furthermore, there is evidence that pass rates for the MRCPsych examination are higher for women than men (51.9\% for part I $v .39 .8 \%$ for men and $54.0 \%$ for part II $v$. $45.1 \%$ for men), ${ }^{14}$ although such statistics are indicators of overall academic ability rather than performance in research.

There are important gender-based differences in selfassessed competencies of research knowledge and skills, which are thought to influence women's decisions about applying for promotion. ${ }^{15}$ Similarly, many women report anecdotally that despite academic and professional accomplishments, they have a persistent sense that somehow they do not deserve their status/position. ${ }^{16}$ Although such doubts are also found in senior men, they are more common in high-achieving women, ${ }^{16}$ and if persistently held, such beliefs are likely to impede further career progression.

\section{Are women less ambitious?}

Gender stereotypes, such as that women are less ambitious or career-minded than men, have been used to explain women's lack of career progression. ${ }^{17}$ However, the rise in the number of young women in medical schools points to early ambition and there is a lack of evidence to support or refute an assumption of less ambition in later years. Evidence does show that female academics have more concerns about potential conflict between being a parent and having a career, and often suffer 'role strain', or 'a divided or uncertain sense of identity experienced many times at all stages of their professional career. ${ }^{18}$ In addition, women at all career stages are less likely than men to recommend parenting to their peers, ${ }^{19}$ which suggests that academia does not facilitate the balancing of a professional career and family responsibilities. ${ }^{20}$

\section{Are women discriminated against?}

Despite large and increasing numbers of women in medical practice, experiences of gender-based discrimination and sexual harassment remain widespread. ${ }^{21}$ Few studies have examined gender discrimination and sexual harassment among academic medical faculty, and those that have tend to have been based on small samples or populations at only one site or in one discipline. In a national survey in the USA of 24 randomly selected medical schools, $77 \%$ of women faculty reported gender-based discrimination (defined as gender-based behaviours, policies and actions that adversely affect work by leading to disparate treatment or creation of an intimidating environment) and harassment (covering a spectrum from generalised sexist remarks and behaviours to coercive sexual advances, and from unconscious patronisation and subtle innuendo to blatant sexual threats). ${ }^{22}$

In relation to promotion, women are promoted more slowly than men and are less likely to achieve a professorial position even when the amount of time they have spent on the medical school faculty is taken into account. ${ }^{23}$ A study of National Health Service hospitals in Scotland found that even after part-time working, years since graduation and all other covariates are controlled for, women are less likely to be promoted than men as hospital consultants. ${ }^{24}$

\section{Organisational barriers}

In addition to experiences of gender-based discrimination, the nature of academic medicine gives rise to organisational barriers to career progression for women, with perhaps the most serious being limited opportunities to work part-time. For instance, fewer than 20 of the 784 tenure track, nontenure track, or Medical Center Line Faculty at Stanford University (USA) have less than full-time schedules. $^{25}$ Furthermore, research shows that significantly more women than men indicate that the inability to work parttime is an obstacle to their career success (22\% of women $v$. $3 \%$ of men). ${ }^{26}$ The same study also highlights other barriers to career progression, such as a lack of on-site childcare provision at work and meetings that are scheduled for evenings or weekends.

\section{Lack of networking opportunities, role models and mentors}

Compared with their male colleagues, women experience reduced access to informal networks, possibly owing to the time commitment required for effective networking. They suffer from reduced access to information, particularly that supplied by 'the grapevine', and thus miss out on information relevant to career advancement such as advice on applying for research grants and promotion procedures. ${ }^{27}$

Role models are vital; not only can role models lead by example in terms of work culture and work-life balance, but 
junior women that can see other women in senior posts are encouraged to aspire to the same position. ${ }^{12}$

Women report greater difficulty than men in finding mentors; ${ }^{28}$ this may be because there are still so few senior women with whom they can engage. In a study of cross-gender and same-gender mentoring relationships, Ragins et $a l^{29}$ found that compared with other gender combinations, female mentees with female mentors were more likely to agree with the idea that their mentor served a role-modelling function. Some women feel that advice or mentoring from male colleagues is less applicable because they lack experience with career-oriented women and/or find it easier to relate to women in social roles rather than professional roles. ${ }^{3,30}$

Evidence shows that women with mentors report more publications and more time spent on research activity than those without mentors, and women with a role model reported higher overall career satisfaction. ${ }^{31}$ It has been argued that women's chances of promotion would be improved if they could access mentors, role models and networks for information and support. ${ }^{17}$

\section{Measures of success and productivity}

Promotion criteria used in universities traditionally require academic productivity in the shape of research, the amount of grant funding and number of publications. This acts as a barrier to women as they tend to have higher lecturing, administration, and pastoral workloads when compared with their male counterparts. ${ }^{32}$ Women are less likely to obtain research funding, ${ }^{6}$ or have high publication records, ${ }^{9}$ than men. When women apply for grant money they are just as successful as men, but they are less likely to apply. ${ }^{33}$ Data from a survey of 3090 academic staff drawn from higher education institutions in the UK shows that grant applications are lower among female academics with dependent children; only $50 \%$ applied for grants $v .62 \%$ of men with families. ${ }^{33}$

\section{The impact of career breaks and part-time working}

Todd \& Bird recognise that women's academic career patterns do not fit the traditional model of academia, in which there is a high productivity at the start of one's career and a slower pace later. ${ }^{17}$ Instead, women's work-life balance and domestic responsibilities mean that they are more likely to take career breaks and/or work less than fulltime in their early years while establishing their families, with productivity then increasing after these early years. Therefore early research output can be heavily compromised by maternity leave, ongoing responsibilities of childcare and household tasks. ${ }^{34}$ The Women in Academic Medicine report ${ }^{12}$ found that $58 \%$ of female respondents had taken a career break compared with $10 \%$ of males, and that since their first appointment in medicine, $38 \%$ of female respondents but only $6 \%$ of male respondents had periods of working less than full time. It is not clear whether, when assessing academics' performance, particularly in the current economic climate, the rate of outputs, in terms of grants and publications, is adjusted appropriately to account for parttime working and for career breaks.

\section{Experiences outside work}

Research shows that the family situations and experiences outside work differ for men and women, and that this may have an impact on women's positions within academic departments. Data collected by Shollen et al from the University of Minnesota Medical School reveal a striking difference between men and women in the number of hours spent on family and household responsibilities per week, with women reporting spending an average of 31 hours per week on these tasks and men spending 19 hours per week. ${ }^{26}$ In addition, women are less likely to have a partner who is either part-time employed or not employed outside the home (only $12 \%$ of women $v .59 \%$ of men) and are therefore less likely to have help from their partner with family and household responsibilities. ${ }^{26}$

Yet the impact of a family on work does not have to be negative. Outside help can be sought for household chores and emotional relationships with children and family can be very supportive and help with keeping a sense of perspective. A study reported in the Conference Proceedings of British Psychological Society by Beninger ${ }^{35}$ compared the challenges faced by 60 women academics from the UK, Australia and the USA in balancing work and non-work responsibilities. The more desirable work-life balance promoted by institutional and governmental policies in Australia was found to reduce stress and minimise guilt among academic women, specifically with respect to childcare.

\section{Interventions}

A number of interventions have been proposed to address the under-representation of women in senior academia and make it easier for women to fulfil their professional potential. These include implementing arrangements for less than full-time working, making promotions criteria and processes explicit and transparent, methods to increase the visibility of female academics and to recognise the impact of career breaks on career development, integrating gender equality into procedures and policies, having a diversity of staff on appointments committees and panels, and provision and monitoring of mentoring. ${ }^{12}$ Mentoring is defined as 'the process whereby an experienced, empathic individual guides another individual in the development and re-examination of their own ideas, learning, and personal and professional development'. ${ }^{36}$ Mentoring can make a substantial contribution to an individual's career development in academic medicine, particularly in areas of research, publications and promotion, by providing junior academics with a means to find out more about career management and institutional networking and being aware of what is appropriate to the stage of career progression. ${ }^{37,38}$ Mentoring has also been recognised as a way to improve the success of those perceived as disadvantaged minorities in clinical academia (women can be considered to be a minority among successful clinical academics), ${ }^{39}$ as well as promoting the advancement of a diverse faculty. ${ }^{40}$

A number of interventions, including mentoring, leadership development, education of faculty about the nature of gender-based obstacles and motivation for change, 
and academic rewards, were implemented at Johns Hopkins University School of Medicine between 1990 and 1995 to correct gender-based career obstacles reported by women faculty. ${ }^{41}$ Results showed more junior women being retained and promoted, with a $550 \%$ increase in the number of women at the associate professor rank over 5 years. Furthermore, a half to two-thirds of women faculty reported improvements in timeliness of promotions, manifestations of gender bias, access to information needed for faculty development, isolation and salary equity.

A new project, the Women's Advancement Initiative, based at the Institute of Psychiatry, King's College London, has been developed to identify the issues influencing career progression for UK women in academic posts in psychiatry and medicine, and to develop a series of interventions to reduce the gender gap in senior academic roles. Based on the Department of Health report, Women Doctors: Making a Difference, ${ }^{42}$ which recommends improved access to mentoring and career advice, as well as the outcome of local focus groups, a pilot scheme offering mentoring to women in academic posts was launched at the Institute of Psychiatry in July 2008. The scheme aims to deliver confidential support and career development (that is separate from appraisal) within a formal mentoring scheme structure in which mentors receive training and support. The scheme has proven popular, with 46 mentoring pairs formed. The scheme will be evaluated at 6 months and again at 12 months after the initial formal mentoring relationships have begun. Our intention is that this pilot will inform a randomised controlled trial of mentoring to be trialled at the Schools of Medicine and Biomedical and Health Sciences, King's College London; to our knowledge, this will be the first randomised controlled trial of mentoring in an educational setting in the UK.

\section{Conclusion}

Women are under-represented in senior roles within academic psychiatry. One potential explanation, with some research evidence to support it, is that women lack mentors and networking opportunities compared with their male counterparts. Individual factors such as personality, confidence, perceptions of barriers or opportunities, and sheer persistence and patience will always be important in achieving success, but organisational strategies to improve gender inequality should not be overlooked as important levers for change. The provision of initiatives such as formal mentoring schemes to support women with career progression, coupled with reform to ensure transparency in performance and promotion procedures, underpinned by systematic wide-ranging integration of gender equality into culture, policies and programmes, will be vital for institutions that are serious about equality.

\section{Acknowledgement}

We thank Melanie Abas (Senior Lecturer at the Institute of Psychiatry, King's College London) for her very helpful suggestions and comments based on an earlier version of the manuscript.

\section{About the authors}

Rina Dutta is an MRC Research Fellow at the Institute of Psychiatry, King's College London, and an Honorary Consultant Psychiatrist for the National Affective Disorders Service at the South London and Maudsley NHS Foundation Trust. Sarah L. Hawkes is the Athena SWAN Charter Coordinator at Equality Challenge Unit. Amy Iversen is an Interim Senior Lecturer in Academic Psychiatry at the Institute of Psychiatry in London and a Consultant Liaison Psychiatrist at King's College Hospital. Louise Howard is a Reader in Women's Mental Health and Head of the Section of Women's Mental Health at the Institute of Psychiatry, King's College London, and an Honorary Consultant Psychiatrist at the South London and Maudsley NHS Foundation Trust.

\section{References}

1 Wilson S, Eagles JM. The feminisation of psychiatry: changing gender balance in the psychiatric workforce. Psychiatr Bull 2006; 30: 321-3.

2 Medical Schools Council. Women in Clinical Academia: Attracting and Developing the Medical and Dental Workforce of the Future. Medical Schools Council, 2007.

3 Bickel J. Women in academic psychiatry. Acad Psychiatry 2004; 28: 285-91.

4 Nonnemaker L. Women physicians in academic medicine: new insights from cohort studies. N Engl J Med 2000; 342: 399-405.

5 British Medical Association. Encouraging Women to Work in Academic Medicine. BMA, 2006

6 Blake, M. Who Applies for Research Funding? Key Factors Shaping Funding Application Behaviour among Men and Women in British Higher Education Institutions. National Centre for Social Research, 2000.

7 Waisbren S, Bowles H, Hasan T, Zou KH, Emans SJ, Goldberg C, et al. Gender differences in research grant applications and funding outcomes for medical school faculty. J Women's Health 2008; 17: 207-14.

8 Laine C, Turner BJ. Unequal pay for equal work: the gender gap in academic medicine. Ann Intern Med 2004; 141: 238-40.

9 Levey BA, Gentile NO, Jolly HP. Comparing research activities of women and men faculty in departments of internal medicine. Acad Med 1990; 65: 102-6.

10 Jagsi R, Tarbell NJ, Henault LE, Chang Y, Hylek EM. The representation of women on the editorial boards of major medical journals: a 35-year perspective. Arch Intern Med 2008; 168: 544-8.

11 Carr PL, Ash AS, Friedman RH, Scaramucci A, Barnett RC, Szalacha L, et al. Relation of family responsibilities and gender to the productivity and career satisfaction of medical faculty. Ann Intern Med 1998; 129: $532-8$.

12 British Medical Association. Women in Academic Medicine: Developing Equality in Governance and Management for Career Progression. BMA, 2008

13 Nonnemaker L. Women physicians in academic medicine: new insights from cohort studies. N Engl J Med 2000; 342: 399-405.

14 Oyebode F, Furlong E. MRCPsych examinations: cumulative results 1997-2002. Psychiatr Bull 2007; 31: 61-4.

15 Bakken LL, Sheridan J, Carnes ML. Gender differences among physicianscientists in self-assessed abilities to perform clinical research. Acad Med 2003; 78: 1281-6.

16 Clance P, Imes S. The impostor phenomenon in high achieving women: dynamics and therapeutic intervention. Psychoth Theory Res Practice 1978; 15: 1-7.

17 Todd P, Bird D. Gender and promotion in academia. Equal Oppor Int 2000; 19: 1-16.

18 Symonds A. Emotional conflicts of the career woman: women in medicine. Am J Psychoanal 1983; 43: 21-37.

19 Cujec B, Oancia T, Bohm C, Johnson D. Career and parenting satisfaction among medical students, residents and physician teachers at a Canadian medical school. CMAJ 2000; 162: 637-40. 
20 Palepu A, Herbert CP. Medical women in academia: the silences we keep. CMAJ 2002; 167: 877-9.

21 Frank $E$, Brogan $D$, Schiffman $M$. Prevalence and correlates of harassment among U.S. women physicians. Arch Intern Med 1998; 158: $352-8$

22 Carr PL, Ash AS, Friedman RH, Szalacha L, Barnett RC, Palepu A, et al Faculty perceptions of gender discrimination and sexual harassment in academic medicine. Ann Intern Med 2000; 132: 889-96.

23 Tesch BJ, Wood HM, Helwig AL, Nattinger AB. Promotion of women physicians in academic medicine. JAMA 1995; 273: 1022-5.

24 Mavromaras K, Scott A. Promotion to hospital consultant: regression analysis using NHS administrative data. BMJ 2006; 332: 148-51.

25 Boulis AK, Jacobs JA. The Changing Face of Medicine: Women Doctors and the Evolution of Healthcare in America. ILR Press, 2008.

26 Shollen SL, Bland CJ, Finstad DA, Taylor AL. Organizational climate and family life: how these factors affect the status of women faculty at one medical school. Acad Med 2009; 84: 87-94.

27 Gardiner M, Tiggemann M, Kearns H, Marshall K. Show me the money! An empirical analysis of mentoring outcomes for women in academia. Higher Educ Res Dev 2007; 26: 425-42.

28 Sambunjak D, Straus SE, Marusic A. Mentoring in academic medicine: a systematic review. JAMA 2006; 296: 1103-15.

29 Ragins BR, McFarlin DB. Perceptions of mentor roles in cross-gender mentoring relationships. J Vocat Behav 1990; 37: 321-39.

30 Brown A, Swinyard W, Ogle J. Women in academic medicine: a report of focus groups and questionnaires with conjoint analysis. J Womens Health 2003; 12: 999-1008.

31 Levinson W, Kaufman K, Clark B, Tolle S. Mentors and role models of women in academic medicine. West J Med 1991; 154: 423-6.
32 Bagilhole B. Too little too late? An assessment of national initiatives for women academics in the British university system. Higher Educ Europe 2000; 25: 139-45.

33 Blake M, LaValle I. Who Applies for Research Funding? National Centre for Social Research, 2000

34 Howard L. Women in academic psychiatry. Psychiatr Bull 2003; 27: 321-2.

35 Beninger A. Women in academia: a cross-cultural perspective on work life balance. Published in The British Psychological Society Annual Conference Proceedings 2010 (http://www.bps.org.uk/conferencesand-events/proceedings/proceedings_home.cfm?\&ResultsType = Abstracts $\&$ ResultSet_ID =5562\&FormDisplayMode =view $\&$ frmShowSelected=true\&localAction=details).

36 Standing Committee on Postgraduate Medical and Dental Education (SCOPME). An Enquiry into Mentoring, Supporting Doctors and Dentists at Work. SCOPME, 1998.

37 Pololi L, Knight S. Mentoring faculty in academic medicine: a new paradigm. J Gen Intern Med 2005; 20: 866-70.

38 Allen T, Eby L, Poteet M, Lentz E, Lima L. Career benefits associated with mentoring for proteges: a meta-analysis. J Appl Psychol 2004; 89 127-36.

39 Selwa L. Lessons in mentoring. Exp Neurol 2003; 184: S42-7.

40 Mark S, Link H, Morahan PS, Pololi L, Reznik V, Tropez-Sims S. Innovative mentoring programs to promote gender equity in academic medicine. Acad Med 2001; 76: 39-42.

41 Fried L, Francomano C, MacDonald S, Wagner E, Stokes E, Carbone K, et al. Career development for women in academic medicine: multiple interventions in a department of medicine. JAMA 1996; 276: 898-905.

42 Baroness Deech. Women Doctors: Making a Difference. Report of the Chair of the National Working Group on Women in Medicine. Department of Health, 2009. 